\title{
Evaluating the environmental and social net-worth of controlling alien plant invasions in the Inkomati catchment, South Africa
}

\author{
Rashid Hassan' and Siphokuhle Mahlathi' \\ ${ }^{1}$ Centre for Environmental Economics and Policy in Africa (CEEPA), University of Pretoria, Pretoria, South Africa
}

The present study attempted to bridge some gaps in the existing literature evaluating the net economic worth of South Africa's Working for Water (WfW) programme for eradicating invasive alien plant species (IAPS). Specifically, the study employed the social benefit-cost analysis (BCA) methodology to assess the impact of accounting for the opportunity cost of invested capital funds and treating labour as a social benefit on the social worthiness of the WfW programme in the Inkomati catchment. The study also used improved measures of the value of other ecosystem services, particularly the carbon sequestration values. Results of the social BCA provided strong empirical evidence in support of the continuation of IAPS eradication activities, as economically and socially worthwhile investment of the country's resources. The programme generates higher net worth under lower rates of discounting future values. This confirms the importance of the water-saving benefits, which continue theoretically for ever, at zero cost to the society, as all direct and indirect financial costs cease upon completion of the eradication operations. The social net worth of the IAPS eradication programme obviously increases when expenditure on labour wages was considered a social benefit rather than a direct financial cost, even under strict project funding scenarios that require funding through private capital markets, i.e., paying commercial rates of interest. However, more strategic planning for the control of IAPS is critically important given their high cost. Challenges facing the sustainability of IAPS eradication programmes in the study area and South Africa include: raising sufficient funding from private and public sources, and introducing incentive systems to encourage higher collaboration and participation of private landowners in the currently primarily publicly driven IAPS eradication efforts. The study also suggests a number of policy and technological reforms to address the said challenges.

\section{INTRODUCTION}

The spread of invasive alien plant species (IAPS) has accelerated in South Africa (SA) over the past few decades as a result of increasing human interventions and consequent rapid changes in land use (i.e. introduction of alien plant species for various purposes). It is estimated that IAPS now cover about $10 \%$ of the country, which is an area almost equivalent to the size of Gauteng Province (Le Maitre et al., 2000). IAPS have both positive and negative ecological and economic effects (Pyšek et al., 2012; Kraaij et al., 2017). Negative impacts of IAPS range from lost agricultural productivity to damage to sensitive ecosystems, human health and biodiversity (Van Wilgen et al., 2008). Of particular importance to SA is the impact of IAPS on stream flow and hence the country's scarce water resources. In addition to the reduced availability of water for downstream uses, reduction of runoff by IAPS has important negative impacts on the ecological Reserve required for ecosystem health (Van Wilgen and De Lange, 2011). A recent study by Le Maitre et al. (2016), using new data and improved models, estimated that an equivalent of $2.9 \%$ of the mean annual runoff (MAR) in SA is reduced due to IAPS. The value of lost volumes of water translates into higher water prices for agricultural and urban users, reduced recreational services (Hosking and Du Preez, 2004), as well as costs of required additional water treatment and purification (Van Wilgen and De Lange, 2011).

To address the problem of IAPS, a national programme for their eradication, Working for Water (WfW) was established in 1995 to restore important ecosystem services such as water and biodiversity (Van Wilgen et al., 2012). Over the 20-year period since its inception, the WfW programme has achieved initial and follow-up clearing of IAPS from 2.5 million ha a very high cost of an estimated 1.5 billion ZAR/a (Van Wilgen and Wannenburgh, 2016; Van Wilgen and Wilson, 2018). Large financial resources are clearly needed for accomplishing the full objectives of the IAPS eradication programme.

Research on the costs and benefits of the programme is, therefore, needed to help policymakers make informed decisions for efficient allocation of public funds between competing uses. A number of studies have been carried out to evaluate the economic impact of the WfW programme. The common finding of all studies to date is that IAPS clearing programme has resulted in a significant increase in stream flow and generated positive economic returns on investment, i.e., benefits of the programme exceeded its costs (Marais et al., 2004; Marais and Wannenburgh, 2008; Prinsloo et al., 2009; Mudavanhu et al., 2017a; Nkambule et al., 2017; Stafford et al., 2017). The bulk of previous studies, however, did not account for impacts on many other important ecosystem services (e.g. non-water and non-timber benefits such as biodiversity and carbon sink values). Also, none of the reviewed studies has accounted for the social benefits from labour employment and the opportunity cost of invested capital funds. Thirdly, except for a few national studies (Van Wilgen

\section{CORRESPONDENCE}

Rashid Hassan

\section{EMAIL}

rashid.hassan@up.ac.za

\section{DATES}

Received: 23 November 2018

Accepted: 4 December 2019

\section{KEYWORDS}

invasive alien vegetation water

carbon benefits social benefit-cost analysis Africa

\section{COPYRIGHT}

() The Author(s)

Published under a Creative Commons Attribution 4.0 International Licence (CC BY 4.0) 
et al., 2008; Van Wilgen and De Lange, 2011; Le Maitre et al., 2016; Stafford et al., 2017) there has been a clear bias in focus on the Western Cape region, and particularly the fynbos biome. The present study attempts to contribute to bridging some of the above gaps through conducting an evaluation of the social benefits and costs of investing in eradication of IAPS in SA. The study was carried in the Mpumalanga Province, another region covered by the WfW programme operations but where no such study has yet been undertaken.

\section{APPROACH AND METHODS}

Our comprehensive review of the relevant literature identified a number of gaps. One weakness common to studies evaluating the economic net-worth of IAPS eradication programmes in SA relates to their treatment of clearing costs. All studies, for instance, utilized estimates of total clearing costs, and none attempted to separate and treat differently expenditure on labour wages as a potential social benefit from employment opportunities created by these programmes. Several examples are found in the relevant analytical and empirical literature where labour input in public projects is treated as a source of both costs and social benefits, particularly under high involuntary unemployment, as is the case in SA (see Haveman and Farrow, 2011; Batrik, 2012; Robalino and Walker, 2017). Similarly, none of the reviewed studies has accounted for the opportunity cost of funds invested (i.e. the capital component), which is a standard benefit-cost analysis practice. Secondly, while some consistency is observed in the methods used to quantify water savings from clearing IAPS across these studies, they have significantly diverged in approaches employed to value and measure impacts on water and other ecosystem services. Most of the studies that attempted to account for non-water values relied on hypothetical scenarios on potential streams of costs and benefits considered in simulation modelling exercises, including rates of removal and regrowth of IAPS, and rehabilitation of cleared areas (Gaertner et al., 2012; Turpie and Heydenrych, 2000; van Wilgen et al., 2008; Mudavanhu et al., 2017a). Thirdly, the bias in the focus on the Western Cape region, and particularly the fynbos biome, is clearly evident in the literature. The current study attempted to test for the impact of accounting for the opportunity cost of invested capital funds and treating labour as social benefit on the social worthiness of the WfW programmes. This study also employed improved measures of the value of other ecosystem services, particularly the carbon sequestration values.

\section{The benefit-cost analysis framework and the concept of net present value}

This study employed social benefit-cost analysis (BCA) tools to evaluate the social net worth of the IAPS eradication programme in the Inkomati river basin. Social BCA is applicable to situations where evaluated projects cause environmental externalities (positive and negative) that are non-private. The outcomes/ impacts of the evaluated alternative investment plans and actions typically are realized over several years to come (project cycle). Therefore, BCA employs the concept of net present value (NPV) to compare the stream of future costs and benefits arising from the projects under consideration. As illustrated below, the length of the project cycle (evaluation period) and the rate at which future flows of benefits and costs are discounted to the present (discount rate) are the two key arguments in computing the NPV of a project.

$$
\mathrm{NPV}=\sum_{t=0}^{T}\left(B_{t}-C_{t}\right) /(1+r)^{t}=\sum_{t=0}^{T}\left[B_{t} /(1+r)^{t}\right]-\sum_{t=0}^{T}\left[C_{t} /(1+r)^{t}\right]
$$

As Eq. 1 shows, the NPV of any project is calculated as the sum of the stream of benefits $\left(B_{t}\right)$ it generates over its cycle of $T$ years, net of costs $\left(C_{t}\right)$, where net benefits $\left(B_{t}-C_{t}\right)$ from the project at time $t(t=0,1, \ldots, \mathrm{T})$ are discounted to the present at the discount rate $r$. In general, if the NPV of a project is positive (NPV $>0$ ) then the project is considered worth undertaking. However, when a choice is to be made between alternative project plans/ options, one needs to compare the magnitude of NPVs generated by considered alternatives, with the one generating the biggest value getting the top rank. Based on the NPV concept specified above, a number of techniques have been developed to evaluate and compare alternative project plans.

\section{The benefit-cost ratio ( $B C R$ )}

This technique simply rearranges Eq. 1 to define the BCR as follows:

$$
\mathrm{BCR}=\sum_{t=0}^{T}\left[B_{t} /(1+r)^{t}\right] / \sum_{t=0}^{T}\left[C_{t} /(1+r)^{t}\right]
$$

The rule then becomes that projects with $\mathrm{BCR}>1$ (i.e. generates present value benefits in excess of project costs) are worth undertaking and the project with the highest BCR ranks top.

\section{The internal rate of return (IRR)}

The internal rate of return (IRR) index is computed by, again, redefining Eq. 1 to compute the rate at which the stream of future net benefits should be discounted to produce a NPV of zero, i.e., present values of the stream of benefits and costs are equal.

$$
0=\sum_{t=0}^{T}\left(B_{t}-C_{t}\right) /(1+r)^{t}
$$

In this specification one needs to solve for the value of $r$ (instead of computing NPV from Eq. 1). The computed value of $r$ is then compared to the chosen social discount rate, and projects that generate IRR higher than the social discount rate are considered worth undertaking, and the one with the highest IRR ranks highest.

\section{Payback period (PBP)}

This technique computes the time it will take a project to pay back the initial resources invested. This is another similar alternative to the IRR, in which one solves for $T$ in Eq. 3, instead of $r$. The project recovering initial investment outlays faster (i.e. over shorter $T$ horizon) are ranked higher.

\section{Costs measured and included in the analysis}

\section{Direct costs of IAPS control}

Direct costs include operating expenditures as well as the opportunity cost of invested capital funds. The WfW programme uses the integrated clearing approach, whereby a mixture of eradication methods are applied in a given area, including mechanical control, chemical and biological control. Eradication techniques applied differ. The spread of alien plants is controlled through intensive efforts from initial clearing, subsequently followed by a series of follow-up procedures. Clearing costs include capital costs (i.e. upfront cost of initial clearing), annual operations, and maintenance costs (e.g. labour, land, herbicides, etc.) as well as the subsequent follow-up operations' costs incurred to avoid regeneration/regrowth of IAPS. Expenditure on labour will also be considered as a source of direct and indirect social benefits from reduced unemployment as will be explained later in the benefits subsection.

This study also estimated the opportunity cost of funds invested in the IAPS clearing programme. Since its start, almost all funding for the WfW programme operations has come from 
public sources. Contributions from other sources, including private entities (i.e. landowners) and some non-governmental organizations (NGOs) have seen a slow growth over the years (Turpie et al., 2008). Regardless of the sources of funding, typical BCA evaluations consider any project to be one option for using financial resources competing with other available alternative investment opportunities in the economy, including interest on depositing these funds in a savings' bank account. Our key informants' survey revealed that no initial capital investments in buying equipment and other fixed assets are incurred by the IAPS clearing activities in the study area. Nevertheless, expenditures on hiring labour and other capital services from contractors (e.g. mechanical clearing, etc.) are also considered to have an opportunity cost of foregone returns on investing such funds in alternative income generation. Accordingly, this study included the opportunity cost of financial resources invested in funding IAPS clearing activities at the ruling commercial banks' savings (lending) interest rate, based on the assumption that funds used to sponsor clearing activities may be borrowed from commercial banks.

\section{Value of the carbon sequestration services of IAPS foregone}

Carbon sequestration by vegetation, such as trees in forests, contribute to climate mitigation by reducing the negative impacts of higher concentrations of carbon in the atmosphere. Consequently, the removal of IAPS may impose costs on the environment, in terms of reduced carbon stocks, as trees have higher carbon storage densities compared to the natural vegetation they replace. It was, therefore, necessary to consider the value of this ecosystem service in our social BCA.

Different methods have been employed to calculate carbonstorage densities, ranging from static to dynamic models, which allow for variability in carbon density by age of trees (Hassan, 2002). Following Christie and Scholes (1995), this study employed the formula below to convert timber volumes to carbon-storage densities:

$$
C=V_{s} \times D_{w} \times F_{c} / F_{s}
$$

where: $C$ is tree biomass carbon density in $\mathrm{MgC} / \mathrm{ha} ; V_{s}$ is stem wood volume in $\mathrm{m}^{3} / \mathrm{ha} ; D_{w}$ is density of wood in $\mathrm{Mg} / \mathrm{m}^{3} ; F_{c}$ is the fraction oven-dried mass that is carbon; and $F_{s}$ is the fraction of whole tree biomass per hectare in stem wood. Carbon lost due to removal of IAPS was then calculated as the difference between carbon sequestration levels with and without IAPS, i.e., between IAPS and the natural vegetation they replaced.

\section{Benefits measured and included in the analysis}

The above costs have been compared to the following benefits from eradicating IAPS:

\section{The value of water saved from streamflow reductions due to IAPS}

Streamflow reductions due to IAPS in excess of that of the original natural vegetative cover, is considered to be an environmental externality of exotic plantations. Therefore, the increased streamflow as a result of removing IAPS is considered a social benefit. This study employed the biomassbased regression model developed by Le Maitre et al. (2000) to estimate the reduction in streamflow due to IAPS relative to the natural vegetation they replaced, based on total above-ground biomass of the exotic vegetation. The hydrological impact model is specified as follows:

Streamflow reduction $(\mathrm{mm})=0.0238 \times$ biomass $\left(\mathrm{g} / \mathrm{m}^{2}\right)$
This equation converts estimates of biomass into estimates of streamflow reduction in millimeter $(\mathrm{mm})$ rainfall equivalents. The biomass is measured in terms of mass of vegetation structure per square meter (volume) $\left(\mathrm{g} / \mathrm{m}^{2}\right)$. The following data is needed to calculate the above values for the study area: (i) total area invaded by each of the three IAPS vegetation types and their location with respect to the riparian zone, e.g., inside or outside the riparian zone, (ii) current allocation of available water between users, and (iii) water tariffs charged on the water using sectors.

\section{The value of the timber of harvested IAPS}

While removal of IAPS deprives communities of harvesting firewood benefits from IAPS vegetation, the volume of timber harvested from clearing IAPS provide direct benefits to society. Due to the difficulty in quantifying the value of firewood used by surrounding communities in the study area, our analysis has only taken into account the value of harvested timber. Harvested IAPS timber is used for different purposes. Our key-informant interviews with the WfW programme area management revealed that timber harvested from clearing IAPS is given as a donation to an eco-furniture company, which processes it into various secondary industry products (e.g. pulp, paper, and furniture). Therefore, the project does not receive revenue from selling harvested IAPS timber. Nevertheless, this is considered a benefit indirectly accruing to the society at large, and hence included in our social BCA. The study, accordingly, required data on market prices of the different IAPS vegetation types to estimate timber benefits.

Other benefits emanating from alien vegetation control include biodiversity conservation, fire protection, higher land productivity, among other ecosystem services, which have not been included in this analysis due to time and financial limitations. Communities also harvest non-timber products from IAPS vegetation (e.g. wild foods, medicinal products, etc.), the value of which has similarly not been included in this study. The value of such timber and non-timber benefits of IAPS to communities represents an opportunity cost of IAPS removal.

\section{WfW project employment benefits}

The relevant literature indicates that expenditure on labour employed in new projects not only represents a direct cost to the project, but is also a source of direct and indirect social benefits, especially under high involuntary unemployment situations (Haveman and Farrow, 2011; Batrik, 2012; Robalino and Wlker, 2017). This is based on the principles of the labour market dynamics, which postulate that the practice of using the market wage rate to value labour overestimates the true opportunity cost of labour when unemployment is high (i.e. overpaying labour). Labour economics suggests that the right measure of the marginal value of labour is the reservation wage (below which the marginal utility from extra leisure time is higher than that from employment). Extra leisure for the unemployed is considered a disutility and they are expected to be willing to work for less than the market wage rate. Therefore the literature suggests that the difference between market wages (typically used to value labour costs) and reservation wages represents a direct social benefit from new jobs (Haveman and Farrow, 2011; Batrik, 2012).

The literature, however, diverges significantly on estimating the generally unobservable reservation wage, ranging from $0 \%$ to $88 \%$ of market wages, depending on whether labour is drawn from those currently involuntarily unemployed (closer to zero\%) or from those already employed in other jobs (Greenberg and Robins, 2008; Boardman et al., 2011). As involuntary unemployment in SA 
is currently very high, plus the fact that one of the main objectives of the WfW programme is to create employment opportunities targeting those currently unemployed, this suggests a very low opportunity cost of leisure time. This study will test the sensitivity of the social net-worth of the WfW to a zero reservation wage rate, which implies that the net social benefit from employment opportunities created by the WfW project will be equal to the market wage rate (i.e. offsetting direct labour costs). This is tested in a separate scenario of the NPV calculations where expenditure on labour wages was left out of project costs (offset by employment benefits to the society at large).

New jobs also generate other indirect social benefits as spill-over effects on non-target markets/sectors when unemployment is high (Greenberg and Robins, 2008; Boardman et al., 201). Accounting for such indirect social benefits, however, requires use of multisector modelling approaches, such as computable general equilibrium models that capture up- and downstream multiplier effects (Batrik, 2012; WB, 2017), which is beyond the scope of our study.

\section{Study area}

Being one of the most severely affected catchments by alien vegetation infestation in the Mpumalanga Province, the Inkomati Water Management Area (IWMA, now part of the InkomatiUsuthu Water Management Area) was chosen for conducting the intended analysis. Situated in the north-eastern part of SA, the IWMA covers an area of $28757 \mathrm{~km}^{2}$, and consists of three main rivers: Komati, Crocodile and Sabie. Rainfall over the IWMA is strongly seasonal and occurs mainly in summer (October to April) (DWA, 2003). The mean annual runoff (MAR) from the entire IWMA is estimated at 3539 million $\mathrm{m}^{3} / \mathrm{a}$ (DWAF, 2003). Reduction in natural runoff is mainly caused by vast commercial plantations and invasive alien vegetation (which covers about $132000 \mathrm{ha}$ ). The impacts of afforestation and alien vegetation on runoff reduction are approximately 53 million $\mathrm{m}^{3}$ and 38 million $\mathrm{m}^{3}$, respectively (DWAF, 2003).

The present study covered 4 quaternary catchments in the study area, namely: the Injaka Dam (X31E), Blyde River/Graskop (X31F), Crocodile (X21C) and Sabie (X31A). The selection of the above catchments in the study area was based on various factors. Firstly, a benchmark was done to ensure that there is reliable cost and water yield data on the selected catchments. Secondly, the relative importance of these catchments was assessed to identify priority catchments in the Mpumalanga Province. Priority catchments are those that contain important diversity, and have species with significant impacts on water yield and other ecosystem services (CSIR, 2011).

Economic activities in the IWMA are mainly centred on irrigation and afforestation (commercial plantations), with related processing industries and a strong eco-tourism industry. Due to its well-watered nature, the IWMA groundwater utilization is relatively small. Most of the current yield from the Komati River is transferred to the Olifants Water Management Area for power generation.

Although land ownership in the study area is shared among both the private and public sector, it was established from the programme managers that only the public sector through the WfW programme is engaged in the eradication of alien vegetation. Only a few private landowners in the study area were willing to participate in alien vegetation control. For example, only 42 ha out of the 860 ha privately owned were cleared at farmers' expense in the Crocodile quaternary catchment. It is important to note that commercial forestry companies in the area maintain IAPS control programmes on all their holdings.

\section{Sources and types of collected data}

Data were collected from various secondary sources, including books, annual reports, journals, and departmental websites, as well as policy documents. In addition, formal in-depth interviews were conducted with key informants, especially the WfW project managers and experts. The types of data collected to allow application of the empirical methods outlined above, included: (i) area invaded by IAPS and the types of species existing in the study area, (ii) project costs covering expenditure on labour, running costs and overheads, (iii) quantities and prices of IAPS timber harvested, (iv) data on the values of water, and (v) carbon. Market prices of commercial timber in SA were gathered from the Department of Agriculture, Forestry and Fisheries (DAFF) database for forestry products. Values of water were estimated using data on water tariffs imposed on different sectors of water use by the Department of Water and Sanitation (DWS). The hydrological data for the study was obtained from the Department of Environmental Affairs (DEA). The study used a recent estimate of a tax proposed on carbon emissions in SA, the implementation of which is under consideration by Government (National Treasury, 2013).

\section{Estimation of the costs and benefits of the project}

The study covered a total area of 54593 ha, of which $12.7 \%$ or 6947 ha are densely infested with IAPS. Little information was available on IAPS clearing activities in the study area prior to 2008 , with major gaps in key elements of the data required to implement the intended BCA. The WfW project management in the study area have better records on IAPS clearing activities since 2008. We could get access to information on the various project operations for the period from 2008 to 2017 covering an area of 3821 ha. This study therefore implemented the BCA for the period following 2008 .

\section{Costs of clearing IAPS in the IWMA}

As explained earlier, the spread of alien plants is controlled through intensive efforts from initial clearing, and a subsequent series of follow-up procedures. Initial clearing is the first stage of IAPS control, while follow-up stages entail the removal of the re-growth of IAPS in an area previously cleared. This study solely focused on woody species (Pinus spp., Acacia mearnsii, and Eucalyptus spp.); mechanical control is the only relevant method in clearing these plants in the study area. Information on the costs of alien vegetation control in the study area at 2017 prices was obtained from the project management for a 9 -year cycle, covering the initial stage and the typically 7 follow-up clearing stages, plus a final maintenance year (see Appendix, Table A1 for details). In some instances, this is not the case as clearing operations are often delayed for lack of funds, and therefore cost estimates used in this study may be less accurate as total eradication costs will increase if IAPS are left to re-establish, for a long time. It is also worth noting that in some quaternary catchments the follow-up treatments go beyond the $7^{\text {th }}$ phase. Since costs incurred in these stages are insignificant, this study considered only 7 follow-up treatments.

\section{Carbon storage benefits lost with removal of IAPS}

Carbon values included in the analysis represent the loss of carbon densities stored in the removed IAPS timber stocks. This value is assumed to cease by completion of clearing activities. Carbon lost due to removal of IAPS was calculated working out carbon sequestration levels with and without IAPS. Carbon storage densities vary among different vegetation types (e.g. depending on total biomass, see Appendix, Table A2 for details). The proposed tax of 120 ZAR per ton of carbon emission in SA (National Treasury, 2013) is used to price carbon sequestration benefits lost. 


\section{Benefits from increased streamflow}

As indicated earlier, this study adapted a biomass-based regression model developed by Le Maitre et al. (2000) to estimate the incremental impact of IAPS on streamflow relative to the original natural vegetation it has replaced (i.e. net change in streamflow reduction). According to the literature, streamflow reduction is positively related to the age of the alien plants, and hence rates of streamflow reductions are proportional to the age of alien vegetation (e.g. plant growth) (Le Maitre et al., 2000). Data obtained on area invaded by types of IAPS species and age classes and their location within and outside the riparian area are presented in Tables A3 and A4, Appendix. This information was used to calculate streamflow reduction associated with the alien vegetation in the study area, details of which are shown in Table A5, Appendix.

Total streamflow reduction in the 3821 ha area considered in our BCA is therefore estimated to be about 7.57 million $\mathrm{m}^{3}$. It is thus expected that eradicating all IAPS in the said area will increase streamflow by an equivalent magnitude. The yearly increase in streamflow due to alien vegetation control, however, depends on the rate of recovery over time and the type of natural vegetation that is re-established (Cooper, 2001). Therefore, the following assumptions were made in order to establish the amount of water which would be saved for utilization by downstream users:

- In the long-run, indigenous vegetation will replace the removed exotic vegetation, and continue to use water, however, at far less rates than exotic vegetation.

- According to the literature, not all the water saved from eradicating alien vegetation will be readily available for use by downstream users (Van Wilgen et al., 2008). Based on expert opinion, the estimated streamflow increase upon removal of IAPS in the study area is thus assumed to proceed as follows: $100 \%$ in the first year, $90 \%, 80 \%, 70 \%, 65 \%, 60 \%, 55 \%$ and $50 \%$ for each subsequent year.

Thus, only portions of the 7.57 million $\mathrm{m}^{3}$ streamflow reduction due to IAPS in the 3821 ha area will be available for downstream use after eradication of IAPS following above ratios, till savings in water flow stabilize at $50 \%$ of the increase in streamflow in the long-run after full eradication (Le Maitre et al., 2000; Van Wilgen et al., 1998). This amounts to approximately 3785 million $\mathrm{m}^{3} / \mathrm{a}$ for use by downstream users in the study area. The above described pattern of gradual change in water savings has been used to calculate the value of water benefits over the years based on actual areas cleared annually (Table 1).

The next challenge in determining water benefits is to decide on a unit value of water. The study assumed that water saved through the eradication programme would be used according to the current water allocation across different water use sectors in the study area (see details in Appendix, Table A5). Based on this, the study used water tariffs charged by the Department of Water and Sanitation (DWS) as of July 2017 across different sectors as the value of water in respective use sectors. One should note, however, that this water pricing regime provides a lower bound on water values as water tariffs in general do not reflect economic prices, and typically contain an implicit subsidy, particularly on major water use sectors, such as agriculture.

\section{Benefits from harvestable timber}

Based on project management assessment, an average rate of extraction in the initial stage of clearing is estimated to be 25 tonnes per invaded hectare. Tonnage of timber harvested in subsequent follow-up and maintenance phases is derived according to the proportion of costs in that phase relative to the initial clearing stage. Information obtained from project management in the study area indicates that a total of 3821 ha has received initial clearing treatment between 2008 and 2017. Volumes of IAPS timber harvested in initial and subsequent clearing stages have accordingly been computed over the 20-year cycle. Consequent impacts of IAPS removal on streamflow and carbon stocks were then calculated employing above assumptions and scenarios as explained in the Appendix. Table 1 presents estimates of volumes of timber harvested, water saved and carbon stocks lost over a 20 -year cycle as a result of IAPS eradication activities in the study area since 2008. As Table 1 shows, no timber benefits are realized (i.e. zero harvests) after 2025, as area initially cleared in 2017 completes its final (maintenance stage) by year 2025, since clearing activities continue for 8 years after the initial phase, as discussed above. However, water-saving benefits continue infinitely after all IAPS have been cleared by 2025 at the $50 \%$ level of streamflow reduction estimate of 3.78 million $\mathrm{m}^{3}$.

\section{RESULTS AND DISCUSSION}

\section{Results of the social benefit-cost analysis}

Above estimated flows are used to implement the social BCA for this case study. The first step in conducting any BCA is to specify the planning horizon over which costs and benefits count. Another important determinant of the net worth of any investment project is the choice of the rate at which future streams of costs and benefits are discounted to the present, i.e., the social discount rate. Choices on these two factors are therefore made first before the various BCA evaluation criteria are derived in subsequent sections.

In the case of a project that involves streams of costs and benefits that continue for some time into the future, questions arise as to how far into the future these financial flows will continue? Two factors determined the choice of the project cycle length for this study. The first is the period for which sufficient information

Table 1. Volumes of timber harvested, water saved and carbon stock removed due to IAPS clearing activities in the study area during the 2008-2017 period estimated over a 20-year project cycle

\begin{tabular}{lcccc}
\hline Year & $\begin{array}{c}\text { Area received } \\
\text { initial clearing } \\
\text { treatment (ha) }\end{array}$ & $\begin{array}{c}\text { IAPS timber } \\
\text { harvested } \\
\left(\mathbf{1} \mathbf{0 0 0} \mathbf{~ m}^{3}\right)\end{array}$ & $\begin{array}{c}\text { Water saved } \\
\left(\text { million } \mathbf{~ m}^{3}\right)\end{array}$ & $\begin{array}{c}\text { Carbon } \\
\text { mass } \\
(\times 1 \text { 000 } \text { ) })\end{array}$ \\
\hline 2008 & 208 & 7.12 & 0.41 & 4.53 \\
2009 & 210 & 9.48 & 0.79 & 6.02 \\
2010 & 274 & 13.27 & 1.25 & 8.43 \\
2011 & 538 & 24.11 & 2.18 & 15.32 \\
2012 & 667 & 32.64 & 3.27 & 20.74 \\
2013 & 484 & 30.64 & 3.90 & 19.47 \\
2014 & 290 & 25.06 & 4.07 & 15.92 \\
2015 & 558 & 32.95 & 4.77 & 20.94 \\
2016 & 422 & 30.56 & 5.17 & 19.42 \\
2017 & 170 & 22.53 & 5.06 & 14.31 \\
2018 & 0 & 14.29 & 4.64 & 9.08 \\
2019 & 0 & 10.91 & 4.32 & 6.93 \\
2020 & 0 & 8.61 & 4.12 & 5.47 \\
2021 & 0 & 6.64 & 3.97 & 4.22 \\
2022 & 0 & 4.81 & 3.86 & 3.06 \\
2023 & 0 & 3.54 & 3.80 & 2.25 \\
2024 & 0 & 2.93 & 3.78 & 1.86 \\
2025 & 0 & 1.55 & 3.78 & 0.99 \\
2026 & 0 & 0.00 & 3.78 & 0.03 \\
2027 & 0 & 0.00 & 3.78 & 0.03 \\
\hline Total & 3821.00 & 281.65 & 70.72 & 179.01 \\
\hline & & & & \\
\hline
\end{tabular}


is available on the IAPS eradication activities in the study area. It is stated above that the WfW project management in the study area provided reliable data on IAPS clearing operations between 2008 and 2017. The second factor relates to the strategy followed for eradication of IAPS. As explained above for the case of the current study, we have knowledge that the IAPS eradication programme needs 9 years to complete (initial year of intensive clearing, 7 years of follow-up stages, and a final year for maintenance operations (Appendix, Table A1). This implies that the last IAPS clearing operation we had information on in 2017 will complete its final clearing phase by 2025 (after 8 years). Accordingly, a project cycle continuing up to 2025 and beyond has been chosen as displayed in Table 1 .

As costs and benefits of public projects/policies often do not occur simultaneously, BCA follows the standard economic practice of discounting future values to their equivalent value today, referred to as 'present value'. Different discount rates have been used in the literature for project evaluation, with strong views arguing for use of lower rates when evaluating projects that take very long to realize benefits (such as investing in climate mitigation), compared to short-term projects.

The average real interest rate on long-term bonds in SA over the past 10 years (2006-2016) was used to discount future values in this study. Nominal interest rates on 10 -year bonds and rates of increase in consumer prices (inflation) were obtained from the South African Reserve Bank (SARB, 2017) to compute an average real interest rate of $8 \%$ for the 2006-2016 period. Sensitivity analyses were carried out to evaluate impacts of lower discount rates on the results of the social BCA.

This study compared the benefits and costs associated with IAPS eradication activities in the study area over a 20 -year project cycle under the following scenarios:

- Scenario 1: It is assumed that capital funds used by the project are provided at no cost. Other direct costs, including expenses paid as compensation to labour, plus the value of carbon sequestration services, are included in the stream of project costs. The value of both timber harvested and water saved constituted the stream of social benefits of the project.

- Scenario 2: applied all assumptions of the first scenario, but accounted for the opportunity cost of capital funds invested in the IAPS eradication activities.

- Scenario 3: adopted all assumptions of Scenario 2 but considered compensation to labour services as a social benefit of employment (job creation) and not a direct financial cost to the IAPS eradication operations.

As explained earlier, all direct costs (labour and other) and benefits from harvested IAPS timber cease upon completion of all clearing operations in 2025. However, benefits of reduced streamflow reduction (saved water) and potential carbon sequestration services lost with eradication of IAPS vegetation continue beyond 2025 The stream of costs and benefits under Scenario I is displayed in Table A6 (Appendix) which clearly shows how the water benefits steadily grow over time to constitute $100 \%$ of the project benefits by completion of IAPS eradication, while carbon benefits seem to fluctuate around $30 \%$ of total costs over the project cycle.

The IAPS eradication programme in the Inkomati study area generated a social NPV of 14.5 million ZAR over the 20 -year period considered (at $8 \%$ discount rate), giving a BCR of 1.6 . These results suggest that investing in eradication of IAPS in the study area pays back its costs in full, with a big surplus amounting to $60 \%$ of the total investment within the 20 -year project cycle considered, and has an IRR much higher than the ruling commercial lending rate of $8 \%$.
Results of the BCA under the three scenarios are summarized in Table 2. The IAPS eradication project in the study area generates a positive NPV and a BCR larger than 1 under all scenarios, suggesting a socially worthwhile investment of the country's resources. Although the results indicate low sensitivity to discount rates, the fact that the project net worth measures (i.e. NPV and BCR) improve under lower rates of discounting future values reflects the higher returns to investment in IAPS eradication, in terms of the larger water savings' benefits, realized at later stages in the project cycle. This also confirms the long-term positive net worth of the WfW programme, as the stream of benefits from water savings into the distant future, beyond completion of IAPS eradication, is significantly larger than the only opportunity cost of lost carbon sequestration service values (Appendix, Table A6).

The above results stand even under the stricter project funding scenario, i.e., capital not free, which requires repayment of the principal amount of funds invested plus a $4 \%$ interest on the borrowed funds at the end of every year of operations. Results also indicate how the social net-worth of the WfW programme increases when expenditure on labour was considered a social benefit rather than a direct financial cost to the programme (Table 2).

It is clear from the results that investment in eradication of IAPS in the study area pays back its full cost within the 20 -year cycle considered, as the lowest BCR for the period was more than 1 . This also suggest that this investment generates a rate of return (i.e. IRR) higher than the $8 \%$ rate at which the lowest BCR of 1 is achieved (Table 2). In conclusion, results of our BCA suggest that eradication of IAPS produces high social returns to justify continued investment of public or even private funds in these programmes.

One should also note that above results highly underestimate the social net-worth of the WfW IAPS eradication efforts. Firstly, it is clear that in the long-run significant net benefits will be realized from water savings for many years beyond the analysed cycle of 20 years. Moreover, the value of a number of other benefits from IPAS eradication were not accounted for in the analysis. For instance, the above analysis assumes that land from which IAPS are cleared does not generate any benefits from potential alternative uses, such as livestock grazing, crop farming, or even harvesting of natural products such as wild food, thatch, etc. (Mudavanhu et al., 2017b). Other potential benefits excluded include economy-wide multipliers effects and biodiversity conservation benefits.

\section{CONCLUSIONS}

Results of the study indicate that investing in eradication of alien vegetation in the study area is economically and socially viable, with benefits due to water savings steadily growing over time to constitute $100 \%$ of total project benefits after completion of eradication activities. Overall, the IAPS eradication project in the study area generates positive NPV and greater than one BCR under all tested project-funding scenarios. These results suggest

Table 2. Results of the benefit-cost sensitivity analysis

\begin{tabular}{|c|c|c|c|c|c|c|}
\hline \multirow[t]{3}{*}{ Scenario } & \multicolumn{6}{|c|}{ Social discount rates } \\
\hline & \multicolumn{2}{|c|}{$8 \%$} & \multicolumn{2}{|c|}{$5 \%$} & \multicolumn{2}{|c|}{$2 \%$} \\
\hline & NPV & $B C R$ & NPV & BCR & NPV & $\mathrm{BCR}$ \\
\hline $\begin{array}{l}\text { Capital at no cost and } \\
\text { wages are expenses }\end{array}$ & 14.5 & 1.6 & 18.0 & 1.6 & 22.9 & 1.6 \\
\hline $\begin{array}{l}\text { Capital at cost and wages } \\
\text { are expenses }\end{array}$ & 1.0 & 1.03 & 1.6 & 1.04 & 2.7 & 1.05 \\
\hline $\begin{array}{l}\text { Capital at cost and wages } \\
\text { are social benefits }\end{array}$ & 8.8 & 1.29 & 11.0 & 1.30 & 14.2 & 1.32 \\
\hline
\end{tabular}

NPV refers to the net present value in 2008 in $R$ million, and $B C R$ is the benefit-cost ratio. 
that the WfW programme represents a socially worthwhile investment of the country's resources. Higher NPV and BCR were obtained under lower rates of discounting future values. This confirms the importance of the water-saving benefits, which continue theoretically forever, at zero cost to society, as all direct and indirect financial costs cease upon completion of the IAPS eradication operations. It is also worth noting that the project's social net worth became even bigger when expenditure on labour wages was considered a social (employment) benefit rather than a direct financial cost, even under strict project funding scenarios that require sourcing funding from private capital markets, i.e., borrowing at commercial rates of interest.

In spite of this strong evidence of the economic worthiness of IAPS eradication, the public sector (government) is the major stakeholder engaged in eradication of IAPS in the study area through the WfW programme, despite the significant share of land (68\%) under private ownership. One of the reasons identified behind this situation was the fact that private benefits from such expensive eradication efforts (mainly value of harvested timber) cease after the first year of clearing. The value of the significant water saving, which represents the main benefit that continues for a long time post-clearing, is viewed as a public good, i.e., enjoyed by the society at large but does not accrue directly to private agents. This weakens the incentive to private owners to commit to the eradication programme.

The results of this study justify the investment of public funds in IAPS eradication. Benefits from removal of IAPS, however, are not earmarked to fund investment in the WfW programme. At least part of the revenue collected from tariffs on the extra water saved through the IAPS removal efforts should be earmarked for funding WfW activities. An appropriate system of payments for ecosystem services (PES) to collect fees from downstream beneficiaries, including farmers, municipal water users (e.g. industrial, services, and domestic), and rural communities, has a potential to raise substantial funds for investments in IAPS removal activities (Turpie et al., 2008).

As noted above, the government is the major player in IAPS eradication in the study area as private landowners upstream have little incentive to bear all costs of clearing IAPS, while not sharing the benefits from their activities enjoyed by downstream users. It is therefore necessary to design a scheme of economic incentives to promote participation of private landowners upstream in IAPS eradication, e.g., through reduced water tariffs, tax relief, or other appropriate rewards.

Good public-private partnerships (PPPs) between government and private agencies are necessary and crucial for projects of such public nature to succeed. This will require efforts to increase the awareness of all stakeholders of the serious social, economic and environmental negative impacts associated with invasion by alien vegetation and the benefits from their eradication. One recommendation to improve collective management of IAPS is to require all owners of large land areas that are invaded by IAPs to develop a management plan for clearing IAPS. Such management plans have already been formulated by some companies like Sappi, in which areas where eradication has been carried out are delineated along with the costs incurred.

Appropriate policy incentives and technological interventions are needed to promote use of alternative measures to control IAPS, particularly biocontrol agents. While such reforms have the potential to increase the efficiency and reduce the costs associated with the mechanical control measures currently being used, their implications for employment must be carefully evaluated.

\section{REFERENCES}

BATRIK T (2012) Including jobs in benefit-cost analysis. Annu. Rev. Resour. Econ. 4 55-73. https://doi.org/10.1146/annurev-resource-110811-114520 BOARDMAN AE, GREENBERG DH, VINNING AR and WEIMER DL (2011) Cost-Benefit Analysis: Concepts and Practice (4 ${ }^{\text {th }}$ edn). Upper Saddle River, Pearson.

CHRISTIE SI and SCHOLES RJ (1995) Carbon storage in eucalyptus and pine plantations in South Africa. Environ. Monit. Assess. 38 231-241. https://doi.org/10.1007/BF00546765

COOPER J (2001) Costs and benefits of eradicating alien invasive vegetation from the upper reaches of the Mhlatuze catchment. Unpublished report, School of Business, University of Natal. University of KwaZulu-Natal Library, Pietermaritzburg.

CSIR (Council for Scientific and Industrial Research (2011) Prioritising quaternary catchments for invasive alien plant control within the working for water Mpumalanga region. Project Report No. CSIR/ ECO/ER/2011/0031/B. CSIR, Pretoria.

DWAF (Department of Water Affairs and Forestry, South Africa) (2003) The environmental impacts of invading alien plants in South Africa. DWAF, Pretoria.

GAERTNER M, DEN BREEYEN A, HUI C and RICHARDSON DM (2012) Impacts of alien plant invasions on species richness in Mediterranean-type ecosystems: A meta-analysis. Progress Phys. Geogr. 33 (3) 319-338. https://doi.org/10.1177/0309133309341607

GREENBERG DH and ROBINS PK (2008) Incorporating nonmarket time into benefit-cost analysis of social programs: An application to the self-sufficiency project. J. Public Econ. 92 766-794. https://doi. org/10.1016/j.jpubeco.2007.09.011

HASSAN R (ed.) (2002) Accounting for Stock and Flow Values of Woody Land Resources: Methods and Results from South Africa. CEEPA, University of Pretoria Press, Pretoria.

HAVEMAN RH and FARROW S (2011) Labor expenditure and benefitcost accounting in times of unemployment. J. Benefit-Cost Anal. 2 (2) Article 7. https://doi.org/10.2202/2152-2812.1081

HOSKING SG and DU PREEZ M (2004) A cost-benefit analysis of the working for water programme on selected sites in South Africa. Water SA 30 143-152. https://doi.org/10.4314/wsa.v30i2.5059

KRAAIJ T, BAARD JA, RIKHOTSO DR, COLE N and VAN WILGEN BW (2017) Assessing the effectiveness of invasive alien plant management in a large fynbos protected area. Bothalia 47 1-11. https://doi.org/10.4102/abc.v47i2.2105

LE MAITRE DC, VAN WILGEN BW, CHAPMAN RA and MCKELLY DH (1996) Invasive plants in the Western Cape, South Africa: Modelling the consequences of a lack of management. J. Appl. Ecol. 33 161-172. https://doi.org/10.2307/2405025

LE MAITRE DC, VERSFELD DB and CHAPMAN RA (2000) The impact of invading alien plants on surface water resources in South Africa: A preliminary assessment. Water SA 26 397-408.

LE MAITRE DC, FORSYTH G, DZIKITIS and GUSH M (2016) Estimates of the impact of invasive alien plants on water flows in South Africa. Water SA 42 659-672. https://doi.org/10.4314/wsa.v42i4.17

MARAIS C and WANNENBURGH A (2008) Restoration of water resources (natural capital) through the clearing of invasive alien plants from riparian areas in South Africa-costs and water benefits. S. Afr. J. Bot. 74 526-537. https://doi.org/10.1016/j.sajb.2008.01.175

MARAIS C, VAN WILGEN BW and STEVENS D (2004) The clearing of invasive alien plants in South Africa: a preliminary assessment of costs and progress. S. Afr. J. Sci. 100 97-103.

MUDAVANHU S, BLIGNAUT JN, NKAMBULE N, VUNDLA T and MOROKONG T (2017a) A cost-benefit analysis of clearing invasive alien plants in the Berg River quaternary catchment of South Africa. Afr, J. Agric. Resour. Econ. 12 (4) 289-321.

MUDAVANHU S, BLIGNAUT JN, VINK N, CROOKES D and NKAMBULE N (2017b) An economic analysis of different land-use options to assist in the control of the invasive Prosopis (Mesquite) tree. Afr. J. Agric. Resour. Econ. 12 (4) 366-411.

NKAMBULE NP, BLIGNAUT JN, VUNDLA T, MOROKONG T and MUDVANHU S (2017) The benefits and costs of clearing invasive alien plants in northern Zululand, South Africa. Ecosyst. Serv. 27 203-223. https://doi.org/10.1016/j.ecoser.2017.04.011

NATIONAL TREASURY (2013) Carbon Tax Policy Paper: Reducing greenhouse gas emissions and facilitating the transition to a green 
economy. URL: http://www.treasury.gov.za/public-comments/CarbonTax-Policy-Paper-2013.pdf

PRINSLOO FW and SCOTT DF (2009) Streamflow responses to the clearing of alien invasive trees from riparian zones at three sites in the Western Cape Province. South. Afr. For. J. 185 1-7. https://doi. org/10.1080/10295925.1999.9631220

PYšEK P, JAROšIK V, HULME P, PERGL J, HEJDA M, SCHAFFNER URS and VILA M (2012) A global assessment of invasive plant impacts on resident species, communities and ecosystems: the interaction of impact measures, invading species" traits and environment Glob. Change Biol. 18 1725-1737. https://doi org/10.1111/j.1365-2486.2011.02636.x

ROBALINO D and WALKER I (2017) Guidance note on the economic analysis of jobs investment projects. Jobs Group, the World Bank, Washington DC. https://doi.org/10.1596/28219

SARB (South African Reserve Bank) (2017) Quarterly Bulletin $4^{\text {th }}$ Quarter 2016. South African Reserve Bank, Pretoria.

STAFFORD W, BIRCH C, ETTER H, BLANCHARD R, MUDVANHU S, ANGELSTAM P, BLIGNAUT J, FERREIRA L and MARAIS C (2017) The economics of landscape restoration: Benefits of controlling bush encroachment and invasive plant species in South Africa and Namibia. Ecosyst. Serv. 27 193-202. https://doi. org/10.1016/j.ecoser.2016.11.021

TURPIE JK, MARAIS C and BLIGNAUT JN (2008) The Working for Water program: Evolution of a payments for ecosystem services mechanism that addresses both poverty and ecosystem service delivery in South Africa. Ecol. Econ. 65 788-798. https://doi. org/10.1016/j.ecolecon.2007.12.024

TURPIE JK and HEYDENRYCH BJ (2000) Economic consequences of alien infestation of the Cape Floral Kingdom's fynbos vegetation. In: Perrings C, Williamson M, Dalmazzone S (eds.) The Economics of Biological Invasions. Edward Elgar, Cheltenham. 214-261. https:// doi.org/10.4337/9781781008645.00018
VAN WILGEN BW, LITTLE PR, GÖRGENS AHM, WILLEMS TA and MARAIS C (1998) Ecosystem services, efficiency, sustainability and equity: South Africa's working for water programme. Trends Ecol. Evol. 13 378. https://doi.org/10.1016/S0169-5347(98)01434-7

VAN WILGEN B, REYERS B, LE MAITRE D, RICHARDSON D and SCHONEGEVEL L (2008) A biome-scale assessment of the impact of invasive alien plants on ecosystem services in South Africa. J. Environ. Manage. 89 336-349. https://doi.org/10.1016/j. jenvman.2007.06.015

VAN WILGEN BW and DE LANGE WJ (2011) The costs and benefits of biological control of invasive alien plants in South Africa. Afr. Entomol. 19 (2) 504-514. https://doi.org/10.4001/003.019.0228

VAN WILGEN BW (2012) Evidence, perceptions, and trade-offs associated with invasive alien plant control in the Table Mountain National Park, South Africa. Ecol. Soc. 17 (2) 23. https://doi. org/10.5751/ES-04590-170223

VANWILGENBW,FORSYTHGG,LEMAITREDC, WANNENBURGH A, KOTZÉ JD, VAN DEN BERG E and HENDERSON L (2012) An assessment of the effectiveness of a large national-scale invasive alien plant control strategy in South Africa. Biol. Conserv. 148 28-38. https://doi.org/10.1016/j.biocon.2011.12.035

VAN WILGEN BW and WANNENBURGH A (2017) Co-facilitating invasive species control, water conservation, and poverty relief: Achievements and challenges in South Africa's Working for Water Programme. Curr. Opin. Environ. Sustainability 19 7-17. https://doi. org/10.1016/j.cosust.2015.08.012

VAN WILGEN BW and WILSON JR (eds) (2018) The status of biological invasions and their management in South Africa in 2017. South African National Biodiversity Institute (SANBI), Kirstenbosch and DST-NRF Centre of Excellence for Invasion Biology, Stellenbosch.

VIEILLEDENT G, FISCHER F, CHAVE J, GUIBAL D, LANGBOUR $P$ and GERARD J (2018) New formula and conversion factor to compute tree species basic wood density from global wood technology database. Am. J. Bot.. https://doi.org/10.1101/274068 


\section{APPENDIX}

\section{Costs of alien vegetation control in the Inkomati area (2017 prices)}

Table A1 presents information obtained from the WfW programme in the Inkomati River catchment. In the initial phase of clearing, total costs are high due to the cost of hiring services of mechanical clearing equipment. The initial phase is also very labour intensive due to the relative difficulty of invasive vegetation management caused by high density of invasion. In this phase, labour costs amount to $1680 \mathrm{ZAR} / \mathrm{ha}$, comprising of both wages and salaries. The major activities at this stage include: felling of trees, and moving and packing of wood to a cleared place. Other associated costs such as herbicide application and hired equipment amount to $1120 \mathrm{ZAR} / \mathrm{ha}$ in this phase. For the purposes of this study, such costs were not separated according to specific activities. In the first follow-up treatment, total clearing costs fell drastically, since at this stage the density of invasion is lower. As the follow-up treatment operations continue, the overall cost of IAPS clearing diminishes, and the average rate of clearing becomes quicker. The quantity of labour required per hectare also declines in a similar fashion until the final maintenance stage is reached, when clearing costs reach their lowest. In the maintenance stage, a very low density of invasion prevails, which is mainly made up of weed seedlings in the areas previously cleared. Small invasions due to re-growth in new areas are also cleared in this phase. There is a negligible difference in costs incurred between the $7^{\text {th }}$ (final) follow-up stage and the maintenance phase.

Table A1. Costs associated with eradicating IAPS in the different clearing stages (2017)

\begin{tabular}{lccc}
\hline Phases of eradication & $\begin{array}{c}\text { Labour costs } \\
(\text { ZAR/ha) }\end{array}$ & $\begin{array}{c}\text { Other costs } \\
\text { (ZAR/ha) }\end{array}$ & $\begin{array}{c}\text { Total cost } \\
\text { (ZAR/ha) }\end{array}$ \\
\hline Initial stage & 1680 & 1120 & 2800 \\
$1^{\text {st }}$ follow-up & 540 & 360 & 900 \\
$2^{\text {nd }}$ follow-up & 372 & 248 & 620 \\
$3^{\text {rd }}$ follow-up & 250 & 172 & 430 \\
$4^{\text {th }}$ follow-up & 168 & 112 & 280 \\
$5^{\text {th }}$ up to $7^{\text {th }}$ follow-up & 120 & 80 & 200 \\
Maintenance stage & 114 & 76 & 190 \\
\hline
\end{tabular}

Source: All information was provided by the WfW programme area project manager. The figures given represent average costs for all density classes in 2017 ZAR values.

\section{Estimation of the carbon sequestration services of IAPS}

As shown in Table A2, different weights are used to convert timber weight to volume for different species. This was necessary since the mass of timber extracted varied by species. The next task is to convert the timber volumes to carbon storage densities.

Table A2. Parameters for estimation of carbon-densities of IAPS (Source: Christie and Scholes (1995)

\begin{tabular}{lcccc}
\hline Species & $\begin{array}{c}\text { Density of } \\
\text { wood } \\
\left(\boldsymbol{D}_{W} \text { in } \mathbf{M g} / \mathbf{m}^{3}\right)\end{array}$ & $\begin{array}{c}\text { Moisture } \\
\text { content at } \\
\text { harvest }(\%)\end{array}$ & $\begin{array}{c}\text { Oven-dried } \\
\text { carbon mass } \\
\text { fraction }\left(\boldsymbol{F}_{c}\right)\end{array}$ & $\begin{array}{c}\text { Stem wood } \\
\text { fraction }\left(\boldsymbol{F}_{s}\right)\end{array}$ \\
\hline Pine & 0.88 & 85 & 0.5 & 0.67 \\
Eucalyptus & 0.86 & 66 & 0.5 & 0.70 \\
Average & $0.87^{\mathrm{a}}$ & 75.5 & 0.5 & 0.69 \\
\hline
\end{tabular}

${ }^{a}$ We note that recent research by Vieilledent et al. (2018) suggests that previous conversion factors (such as this one) underestimate basic wood density by between 4 and $5 \%$.

This study used the averages (i.e. $D_{w}=0.87, F_{c}=0.5$, and $F_{s}=0.69$ ) of the relevant parameters (which are standard in South Africa for different plantation species) to estimate carbon densities of IAPS in the study area, as specified in Eq. 5 (reproduced below):

$$
C=V_{s} \times D_{w} \times F_{c} / F_{s}
$$

$V_{\mathrm{s}}$ values are derived from information on volumes of timber harvested (see Table 1).

\section{Areas invaded by IAPS and age class of alien vegetation within and outside of riparian zones in the Inkomati catchment}

The total area invaded by IAPS (i.e. $6947 \mathrm{ha}$ ) in the study area was divided into riparian zones (5 210 ha or $75 \%$ ) and nonriparian ones (1 737 ha or $25 \%$ ).

Table A3. Average age class of IAPS and area invaded in riparian zones (area $=5210 \mathrm{ha}$ )

\begin{tabular}{lccccc}
\hline Area/age & X21C & X31F & X31E & X31B & $\begin{array}{c}\text { Average } \\
(\mathbf{X 2 , 3 1 C}, \mathrm{F}, \mathrm{E}, \mathrm{B})\end{array}$ \\
\hline Average age Class 1 & 3 years & 3 years & 3 years & & 3 years \\
Average age Class 2 & 8 years & 8 years & 8 years & 8 years & 8 years \\
Average age Class 3 & 15 years & 16 years & & 15 years & 16 years \\
Area under Class 1 & $9 \%$ & $7 \%$ & $36 \%$ & & $13 \%$ \\
Area under Class 2 & $88 \%$ & $79 \%$ & $64 \%$ & $62 \%$ & $73 \%$ \\
Area under Class 3 & $3 \%$ & $14 \%$ & & $38 \%$ & $14 \%$ \\
\hline
\end{tabular}

Class 1 refers to tall alien shrubs (Solanum mauritianum), Class 2 to medium-sized alien trees Acacia mearnsii, medium-sized Eucalyptus, and Acacia mixed spp.), and Class 3 to tall alien trees (Pinus spp., Acacia spp. and Eucalyptus spp.) (Source: Mpumalanga WfW Project management data)

Table A4. Average age class of IAPS and area invaded outside riparian zones (area $=955 \mathrm{ha}$ )

\begin{tabular}{lccccc}
\hline Area/Age & X21C & X31F & X31E & X31B & $\begin{array}{c}\text { Average } \\
(\mathbf{X} 21 C, F, E, B)\end{array}$ \\
\hline Average age Class 1 & 3 years & 3 years & 3 years & & 3 years \\
Average age Class 2 & 8 years & 8 years & 8 years & 8 years & 8 years \\
Average age Class 3 & 15 years & 16 years & & 15 years & 16 years \\
Area under Class 1 & $5 \%$ & $25 \%$ & $4 \%$ & $30 \%$ & $16 \%$ \\
Area under Class 2 & $85 \%$ & $75 \%$ & $80 \%$ & $70 \%$ & $77 \%$ \\
Area under Class 3 & $10 \%$ & & $16 \%$ & & $7 \%$ \\
\hline
\end{tabular}

Source: Mpumalanga WfW Project management data

The literature shows that the species reported in the above table are considered priority species in the study area (CSIR, 2011). Priority species are selected in terms of their impact on streamflow, biodiversity and ecosystems. It is clear from Tables 3 and 4, that the medium-sized alien trees (age structure 2) are the most dominant trees occupying $75 \%$ of the total invaded area in the IWMA. The vegetation structure with the highest average age class is the tall alien trees at 16 years.

\section{Calculating streamflow reduction due to IAPS located in the study area}

The biomass regression equations (Table A5) for three classes of IAPS were adopted from Le Maitre et al. (1996) and used in this study.

Table A5. Biomass regression equations for three classes of IAPS (adopted from Le Maitre et al., 1996)

\begin{tabular}{llc}
\hline Equations & Vegetation class & Biomass equation $\left(\mathbf{g} / \mathbf{m}^{3}\right)$ \\
\hline 1 & Tall alien shrubs & $b=5240 \log _{10}(a)-415$ \\
2 & Medium alien trees & $b=9610 \log _{10}(a)-636$ \\
3 & Tall alien trees & $b=20000 \log _{10}(a)-7060$ \\
\hline a refers to age and $\mathrm{b}$ is biomass &
\end{tabular}




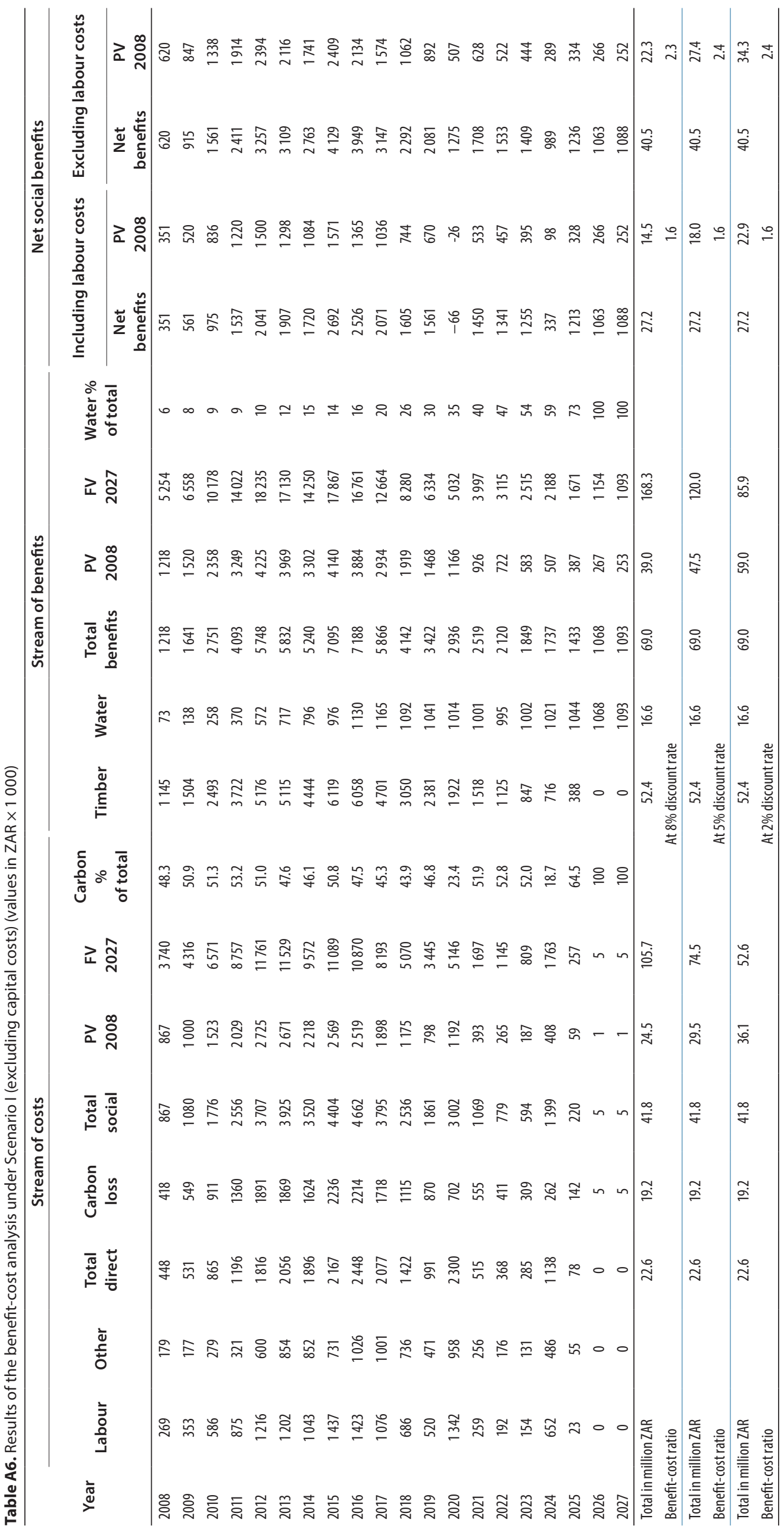


As an example, we derive the streamflow reduction values below in riparian zones where 'tall alien shrubs' occupy $13 \%$ of the invaded area, equivalent to $\mathbf{6 7 7 . 3}$ ha. The average age of this vegetation class is 3 years. Using the biomass equation:

$$
b=5240 \log _{10}(a)-415
$$

we calculate $\boldsymbol{b}=\mathbf{2} \mathbf{0 8 5 . 1}$, and hence the streamflow reduction $(\mathrm{mm}): 0.0238\left(2085.1 \mathrm{~g} / \mathrm{m}^{2}\right)=\mathbf{4 9 . 6 3} \mathbf{~ m m}$. This streamflow reduction $(\mathrm{mm})$ is then converted into $\mathrm{m}^{3}$ as follows:

$\mathrm{m}^{3}=\mathrm{mm} \times$ area (ha) $\times 10=\mathrm{m}^{3}=49.63 \mathrm{~mm} \times 677.3 \mathrm{ha} \times 10=336143.99 \mathrm{~m}^{3}$

Based on the above assumptions the estimated amount of water available for utilization $\left(3785\right.$ million $\mathrm{m}^{3}$ ) is allocated among use sectors following current water allocations shown in Fig. A1, with irrigation taking the largest share $(63 \%)$, followed by industry $(18 \%)$, domestic (10\%), and forestry (9\%) of the total available water. One should note that forestry plantations are typically situated upstream, and hence this assumes (theoretically) that such additional allocations of water to these activities can only be effected through some mechanism of licensing or other enabling policy regimes. However, allocation of their share to industry or domestic uses will not alter the total value as the same tariff rates are charged on these.

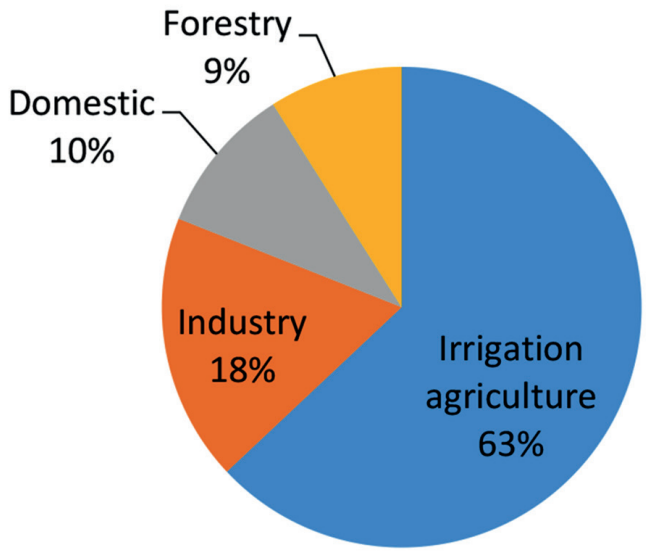

Figure A1. Current water allocation in the study area 